\title{
Medicinal Plants in the Broad-Leaf Mixed Coniferous Forest of Tshothang Chiwog, Bhutan: Floristic Attributes, Vegetation Structure, Ethnobotany, and Socioeconomic Aspects
}

\author{
Ngawang Jamba and B. Mohan Kumar* \\ School of Ecology and Environment Studies, Nalanda University, Rajgir, India
}

The Himalayan Kingdom of Bhutan, located in one of the global biodiversity hotspots, is endowed with abundant floral wealth, including a wide array of medicinal plants (MPs). However, over-exploitation of these resources is widespread, and only a few studies have assessed the richness and diversity of Bhutanese forests and in particular about the MP resources. A vegetation survey was conducted in Tshothang Chiwog, south-eastern Bhutan to characterize the floristic structure of the broad-leaf mixed coniferous forests with a special focus on MPs. A questionnaire survey involving 40 farmers was also conducted to assess the ethnobotanical and socioeconomic aspects of MP extraction. A total of 157 plant species (38 trees, 19 shrubs, 85 herbs and ferns, and 15 climbers), representing 74 families and 137 genera were identified from the study area, of which 69 species (14 trees, 10 shrubs, 38 herbs and ferns, and seven climbers), belonging to 41 families and 69 genera were medicinally important. The most species-rich families of medicinal plants were: Asteraceae (eight spp.), Apiaceae (four spp.), Polygonaceae, Brassicaceae, Zingiberaceae, and Urticaceae (three species each). Herbaceous flora exhibited the highest diversity (Simpson diversity index, $D=0.97$ and Shannon-Weiner index, $H^{\prime}=5.82$ ), followed by trees and shrubs $\left(D=0.95\right.$ and 0.92 and $H^{\prime}=4.86$ and 3.97, respectively). All but one herb showed abundance-to-frequency ratio (A/F) $\geq 0.05$, signifying a contagious distribution pattern (large aggregated distribution). Girth class distribution of trees followed an inverse J-shaped pattern. Results of the ethnobotanic study documented 55 MPs. MP collection, as reported by the interviewees, generally improved the socioeconomic status of the people of Tshothang Chiwog. Apart from improving the livelihood security of the local people, aspects relating to health care and culture are also important. Respondents were also concerned about the declining MP wealth of the Chiwog over the years, due to over-exploitation. Monitoring the plant resources and adopting conservation programmes in the Chiwog, in their opinion, may improve the MP wealth of the locality. The lessons learned from the study may have applicability over the south-eastern part of Bhutan and other regions with similar eco-climatic features.

Keywords: Himalayas, floristic composition, vegetation structure, medicinal plant collection, socioeconomic status

Front. Environ. Sci. 5:96

doi: 10.3389/fenvs.2017.00096 


\section{INTRODUCTION}

Bhutan is endowed with abundant floral wealth including medicinal plants (MPs). Located in one of the world's biodiversity hotspots (Eastern Himalayas), the country has $70.46 \%$ forest cover with over 224 potential MPs, which are broadly categorized into high and low altitude MPs based on their location of occurrence (Wangchuk and Samten, 2009). Medicinal plants are primary ingredients of the traditional health-care systems (gSo-ba rig-pa and folk medicine) of Bhutan (Wangchuk et al., 2009) and they abound in the Bhutanese forests (Govil, 1999; NEC, 2016). Historically, collection of MPs offered a mode of subsistence for the indigenous people of Bhutan and many other countries, and presumably, such operations were occurring at low-impact levels. Over a period of time, however, MPs began to play a more important role in commercial income generation and employment in many ethnic groups and cultures of indigenous peoples (Runk, 1998). Although this led to improvements in the economic status of the collectors (Robbins, 2000; Ticktin et al., 2002), there was widespread over-exploitation of the MP resources in the wild. For example, Wangchuk et al. (2016) reported that Menjong Sorig Pharmaceuticals (MSP), the firm that produces more than 100 poly-ingredient medicines for the traditional gSo-ba-rig-pa hospitals of Bhutan, has been extracting MPs from the Lingzhi region for nearly 50 years, which increased the harvesting pressure on the MP resources in the locality.

As MPs become commercially valuable, their level of extraction increased-often exceeding sustainable levelsthreatening the prospects of long-term revenue generation (Ngawang, 1996; Kala, 2005). With the result, numerous non-timber forest products have come nearer to extinction in many parts of the world (Nepstad et al., 1992; Daniels et al., 1995; Murali et al., 1996). MPs are thus facing growing threats worldwide from damage to their habitats, bioprospecting for alternate sources, and overharvesting of commercially important species (Roberson, 2008). However, only very few studies have assessed the distribution pattern, population status, and ecological pressure that MPs are experiencing in the Bhutanese context (e.g., Wangchuk et al., 2016), presumably because of the inaccessibility of the MP bearing forest areas in the country.

Tshothang Chiwog (a basic electoral precinct of Bhutan), under Lauri Gewog (block), is a part of Sakteng Wildlife Sanctuary in Eastern Bhutan (Figure 1), where the people have traditionally harvested MPs, at low intensities. However, as the demands for MPs increased due to potential contributions on drug discovery, income, and employment, the trend of low-level harvest gradually shifted to more intensive forms (FAO, 1996). This in turn, resulted in large scale extraction of MPs from these forests. For instance, 94,000 kg chiretta (Swertia chirata), $24,000 \mathrm{~kg}$ common madder (Rubia cordifolia), and 5,024 kg star anise (Illicium griffithii) were collected by the farmers of Lauri Gewog in 2007 (Pannozzo et al., 2012). At present, MPs like S. chirata, R. cordifolia, leafless mistletoe (Viscum nepalense), ginseng (Paris polyphylla), and pisa (Parasassafras confertiflora) are primarily regarded as commercial commodities (Pannozzo et al., 2012). Furthermore, the collection of MPs has been a source of income and health security for the inhabitants of Tshothang Chiwog. For example, in 1996-1997, more than 42\% of total cash income of Lauri Gewog was obtained by the sale of $S$. chirata (Tshering, 2006). Similarly, in 2007, a total amount of $\mathrm{Nu}$. $9,23,000$ (USD $\approx 14,290$ ) was made from the sale of MPs, chiefly S. chirata. Different parts of these plants are also used to cure and treat various ailments like a headache, stomach disorder, cough and cold, fractures, fever, etc. (Ugyen, 2004). Of late, the largescale exploitation of MPs (Pannozzo et al., 2012) has reached alarming levels.

Indiscriminate extraction of forest plants may lead to changes in species composition, abundance, stand density, recruitment of individuals and vegetation structure (Shankar et al., 1998; Muraleedharan et al., 2005), which will affect not just the local biodiversity but also other ecosystem services and the livelihood security of the people (Paul et al., 2015). The idea of judicious extraction of MPs to ensure sustainability and for maintaining the diversity of the forests is, therefore, important. However, it is often jeopardized by the ever-increasing demand for such products and the consequential mounting anthropogenic pressures. It is thus, crucial to evolve appropriate conservation and management strategies for MP resources.

Although the MP spectrum may get disturbed during the exploitation of resources, a comprehensive account of the disturbances, imminent threats, ethnobotanical study and related changes in the vegetation attributes of the Chiwog is lacking. Likewise, information relating to MP diversity and structure are also lacking for the Chiwog. Therefore, an attempt was made to elucidate the floristic spectrum and diversity of plants in the broad-leaf mixed coniferous forests of Tshothang Chiwog, the principal forest type of the Chiwog, and to characterize the MP resources for their uses. We hypothesized that although Bhutanese forests are endowed with abundant medicinal plant diversity, over exploitation may pose a serious threat to these resources in the wild, as elsewhere in the world (e.g., Roberson, 2008). Specifically, the study addressed the following questions: (i) what is the floristic spectrum of the broad-leaf mixed coniferous forest of Tshothang Chiwog with a special focus on the MPs? (ii) what are the principal MPs collected by the local people? (iii) what are the therapeutic properties of MPs according to the traditional knowledge? and (iv) what are the impacts of MP collection on the socioeconomic status of the community? Although this study focused on one of the Chiwogs, the results may have wider applicability across other Dzongkhags (Districts) of Bhutan, with similar edaphic and floristic attributes.

\section{MATERIALS AND METHODS}

An ethics approval was not required as per the Nalanda University guidelines and national regulations. However, the dissertation committee of Nalanda University has reviewed and approved the study. Field research work in the State Reserved Forests/Community Forest/ Protected Areas of Bhutan was approved (ex post facto) by the Chairman of the Research Steering Committee, Department of Forests and Park Services, Ministry of Agriculture and Forests, Royal 


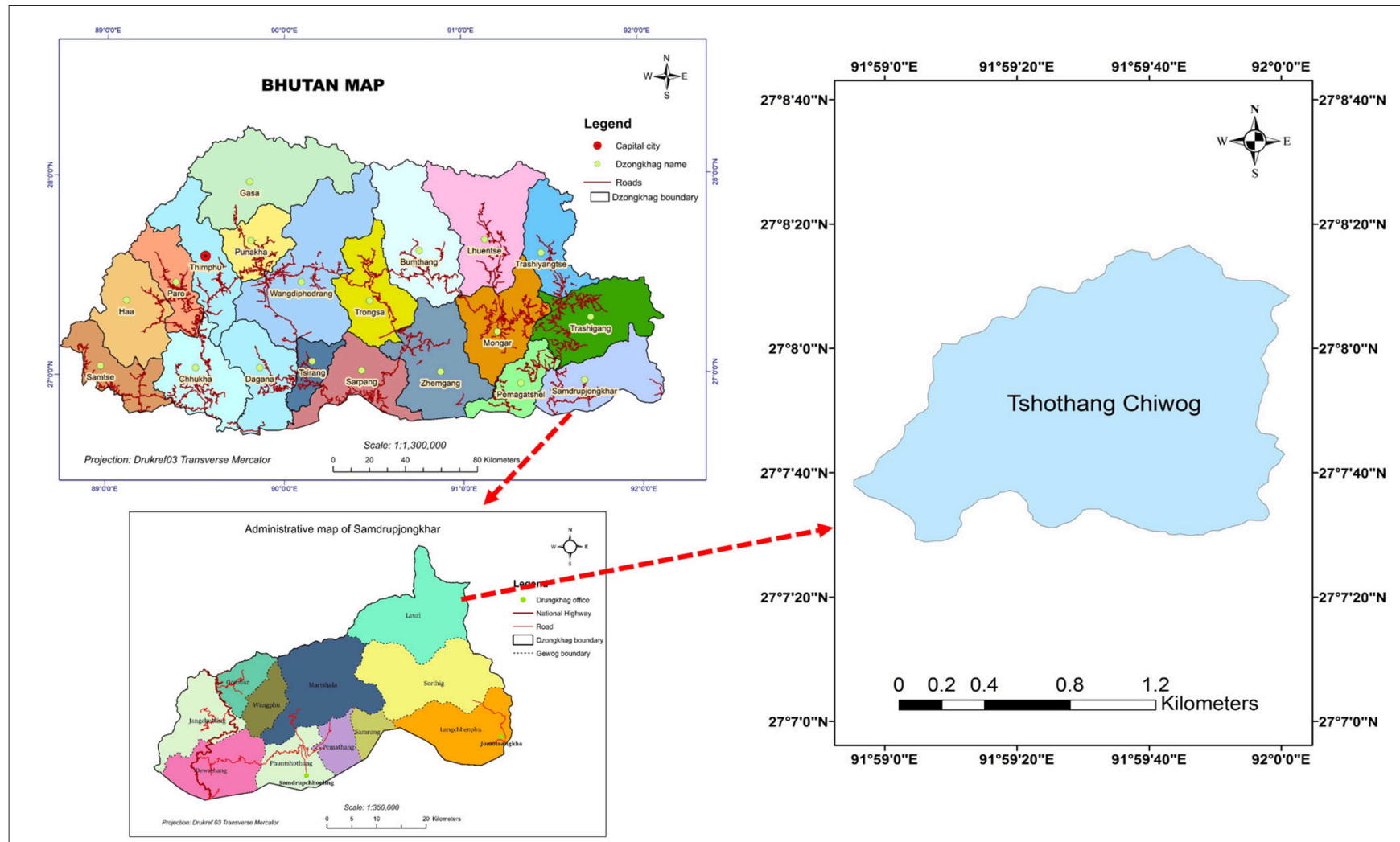

FIGURE 1 | Map of Bhutan showing the location of the study site (Tshothang Chiwog in Lauri Gewog, Samdrup Jongkhar). Bhutan and Samdrup Jongkhar maps reproduced with permission of the National Land Commission, Thimphu.

Government of Bhutan (Ref \# 10126905005A2FEB83D234F). Verbal informed consent was also obtained from all research participants (both focus groups participants and semistructured-interview participants) of the ethnobotanical study according to institutional and national requirements and no minors (non-adults) participated in this research.

\section{Study Site}

The study was conducted in Tshothang Chiwog, Lauri Gewog, South-Eastern Bhutan. The site lies between $27^{\circ} 7^{\prime} 30^{\prime \prime}$ and $27^{\circ} 8^{\prime} 15^{\prime \prime} \mathrm{N}$ latitude and between $91^{\circ} 59^{\prime} 0^{\prime \prime}$ and $92^{\circ} 0^{\prime} 00^{\prime \prime} \mathrm{E}$ longitude (Figure 1). The topography of the Gewog is rugged with an altitude range of 600 to $3,000 \mathrm{~m}$ above mean sea level. Soils in the southern belt of Bhutan covering the study location are mostly fluvisols, which together with cambisols (widespread in the medium-altitude zone) cover $\sim 27 \%$ of Bhutan (FAOUNESCO, 1977). The area experiences a warm humid subtropical climate. Mean maximum temperature recorded at Lauri during the period from November 2014 to September 2017 ranged from $12.1^{\circ} \mathrm{C}$ (January) to $25.3^{\circ} \mathrm{C}$ (July) and mean minimum temperature ranged between $11.6^{\circ} \mathrm{C}$ (January) and $23.6^{\circ} \mathrm{C}$ (July) (source: The National Center for Hydrology and Meteorology, The Royal Government of Bhutan, Thimphu, Bhutan). Mean annual precipitation during the reporting period was $1,052 \mathrm{~mm}$, characterized by a monomodal distribution pattern with most of the precipitation occurring during the months from June to
September. October to March is the dry season. Relative humidity at Lauri ranged from $63 \%$ (January) to $84 \%$ (June). The forests of the Chiwog broadly fall under the category of broad-leaf mixed coniferous forest.

Tshothang Chiwog consists of three villages, viz., Rashuthang, Makhawoong, and Tshothang with 57 households and a total population of 428. A representative area was selected for the study after a reconnaissance. The criteria used for selection of the study location were: (i) abundances of MPs, and (ii) local farmers' dependence on MP collection to improve their livelihood security.

\section{Vegetation Analysis}

A vegetation survey was carried out from 30 November 2016 to 12 January 2017 to assess the floristic diversity and structure of the forest, following the quadrat method. A total of 50 quadrats, of size $10 \times 10 \mathrm{~m}$, was randomly established to characterize the trees (girth at breast height, $\mathrm{GBH} \geq 15 \mathrm{~cm}$ ). Similarly, a total of 50 quadrats of size $5 \times 5 \mathrm{~m}$ nested inside the original $10 \times$ $10 \mathrm{~m}$ quadrats was used to document the shrubs species (low woody perennials generally $<5 \mathrm{~m}$ height). All trees and shrubs, and climbers in each quadrat were enumerated. The girth of trees and shrubs were measured respectively at $1.37 \mathrm{~m}$ and $2 \mathrm{~cm}$ above ground using a measuring tape. For characterizing the herbs, 50 quadrats of size $1 \times 1 \mathrm{~m}$ nested inside the $5 \times 5 \mathrm{~m}$ quadrats were used. Specimens were collected from all quadrats and identified 
by comparing with published reports (Grierson and Long, 1991; Thinley, 2004; Wangchuk and Samten, 2009). All potential MPs of various life forms (trees, shrubs, herbs and ferns, and climbers) were also recorded.

Vegetation data of plant population were quantitatively analyzed for density (no./ha), abundance, frequency, abundanceto-frequency ratio (A/F ratio; Curtis and McIntosh, 1950). The $\mathrm{A} / \mathrm{F}$ ratio was used to interpret distribution pattern of the species. Simpson diversity index (Simpson, 1949), ShannonWeiner index, and important value index (IVI; as a sum of relative density, relative frequency and relative basal area for trees and shrubs and as a sum of relative density and relative frequency for herbs and climbers; Muraleedharan et al., 2005) were computed.

\section{Ethnobotanical and Socioeconomic Aspects}

The ethnobotanical study was undertaken to gather information on the predominant MPs collected by the local people, characterize the traditional knowledge on therapeutic properties of important MP resources in the locality and to elucidate information on the ecological impacts of MP collection. The socioeconomic survey focused on gathering details such as mode of collection, prospects for cultivation and income generated. Information on ethnobotanical and socioeconomic aspects were elucidated through an open-ended focus group discussion and through semi-structured interviews during the month of December 2016, following standard methods for social surveys. The sample size for the socioeconomic survey was determined using Yamane (1967) formula. Accordingly, a total of 40 respondent farmers (heads of the families) were called in for the focus group discussion and interview. The participants were asked to assemble in the local community hall (tshokhang) on an auspicious day according to the Bhutanese calendar (i.e., 29 December 2016, when the farmers were free from field work). Aspects relating to the spectrum of MPs in their locality (using vernacular names), parts used, habit, and the therapeutic values were discussed. Information on ethnobotanical aspects was instantaneously recorded in a field notebook. In parallel, respondents were also interviewed on socioeconomic status using a semi-structured questionnaire, which covered aspects such as personal characteristics of the respondents (age, gender, education), mode of MP collection (e.g., who collects, major products collected, method, frequency, and season of collection), prospects for cultivation (which MPs are cultivated), annual income level (how much income is generated and where the products are sold), and the current scenario and management of MPs (species rank order of abundance, changing patterns of MP availability in the locality, factors causing depletion of MPs, and presence or absence of guidelines for MP collection/management). Information on ethnobotanical aspects and medicinal properties of the plants were supplemented with published information (State of an Environment, 2007; Wangchuk and Samten, 2009; Wangchuk et al., 2011). The data on socioeconomic variables were analyzed using percentage frequency distribution.

\section{RESULTS}

\section{Floristic Composition, Important Value Index, and Diversity of the Broad-Leaf Mixed Coniferous Forest of Tshothang Chiwog, Bhutan}

A total of 157 plant species (38 trees, 19 shrubs, 85 herbs and ferns, and 15 climbers), representing 74 families and 137 genera were identified from the study area (Appendix 1 in Supplementary Material). The most species-rich plant families were: Asteraceae (15 spp.), Poaceae (nine spp.), Solanaceae (seven spp.), Polygonaceae and Urticaceae (five spp. each). Of the total plants encountered in the study area, only 69 species (14 trees, 10 shrubs, 38 herbs and ferns, and seven climbers), belonging to 41 families, and 69 genera were medicinally important (Table 1). The most species-rich families of medicinal plants were: Asteraceae (eight spp.), Apiaceae (four spp.), Polygonaceae, Brassicaceae, Zingiberaceae, and Urticaceae (three species each).

The total density of trees and shrubs was 784 and 1,448 individuals per hectare with a corresponding stand basal area of 24.86 and $5.38 \mathrm{~m}^{2} \mathrm{ha}^{-1}$, respectively (Appendix 1 in Supplementary Material). Mountain bamboo (Borinda grossa: 66 trees $\mathrm{ha}^{-1}$ ), flowering or evergreen ash (Quercus griffithii: 62 trees $\mathrm{ha}^{-1}$ ), and Himalayan blue pine (Pinus wallichiana: 42 trees $\mathrm{ha}^{-1}$ ) contributed the three top tree densities and titeypati (Artemisia dubia: 216 individuals ha ${ }^{-1}$ ), Indian stinging nettle (Girardinia diversifolia: 208 individuals $\mathrm{ha}^{-1}$ ) and blackberry (Rubus fruiticosus: 96 individuals $\mathrm{ha}^{-1}$ ) represented the three top shrub species at the study site. The total per hectare count of herbs/ferns was $1,91,800$ and that of climbers 330. Among the herbaceous plants, S. chirata was the most abundant (13400 plants ha $\left.{ }^{-1}\right)$, followed by saim weed (Chromolaena odorata: 7200 plants ha ${ }^{-1}$ ), P. polyphylla (6800 plants $\mathrm{ha}^{-1}$ ), and elatostema (Elastostema platyphyllum: 6200 plants ha ${ }^{-1}$ ). Asteraceae accounted for 23,600 of the total density of $1,91,800$ individuals $\mathrm{ha}^{-1}$ (Appendix 1 in Supplementary Material).

Importance Value Index (IVI) expresses the overall importance of a species in a community. Q. griffithii, $P$. wallichiana, sunda oak (Lithocarpus elegans) and Chinese sumac (Rhus chinensis) exhibited the three to four top IVI for tree species (Appendix 1 in Supplementary Material). Similarly, A. dubia and S. chirata represented the highest IVI for shrubs and herbs, respectively (Appendix 1 in Supplementary Material). $R$. cordifolia showed the highest IVI among climber species. All plant species showed abundance-to-frequency ratio $(\mathrm{A} / \mathrm{F}) \geq 0.05$, except for P. polyphylla (Melanthiaceae), which had an A/F-value of 0.04 .

The floristic diversity (Simpson's Diversity Index, ShannonWiener Diversity Index) and important attributes (Density, Important Value Index, and Equitability) of all categories of plant species are summarized in Table 2. Simpson's diversity indexes were the highest for the herbaceous species (0.97) and the lowest for climbers $(0.92)$ at this study site. Shannon index $\left(H^{\prime}\right)$ values ranged from 3.69 (climbers) to 5.82 (herbs/ferns). 
TABLE 1 | Density, basal area, percentage frequency, A/F ratio and important value index of medicinal plant species in the broad-leaf mixed coniferous forests of Tshothang Chiwog, Bhutan.

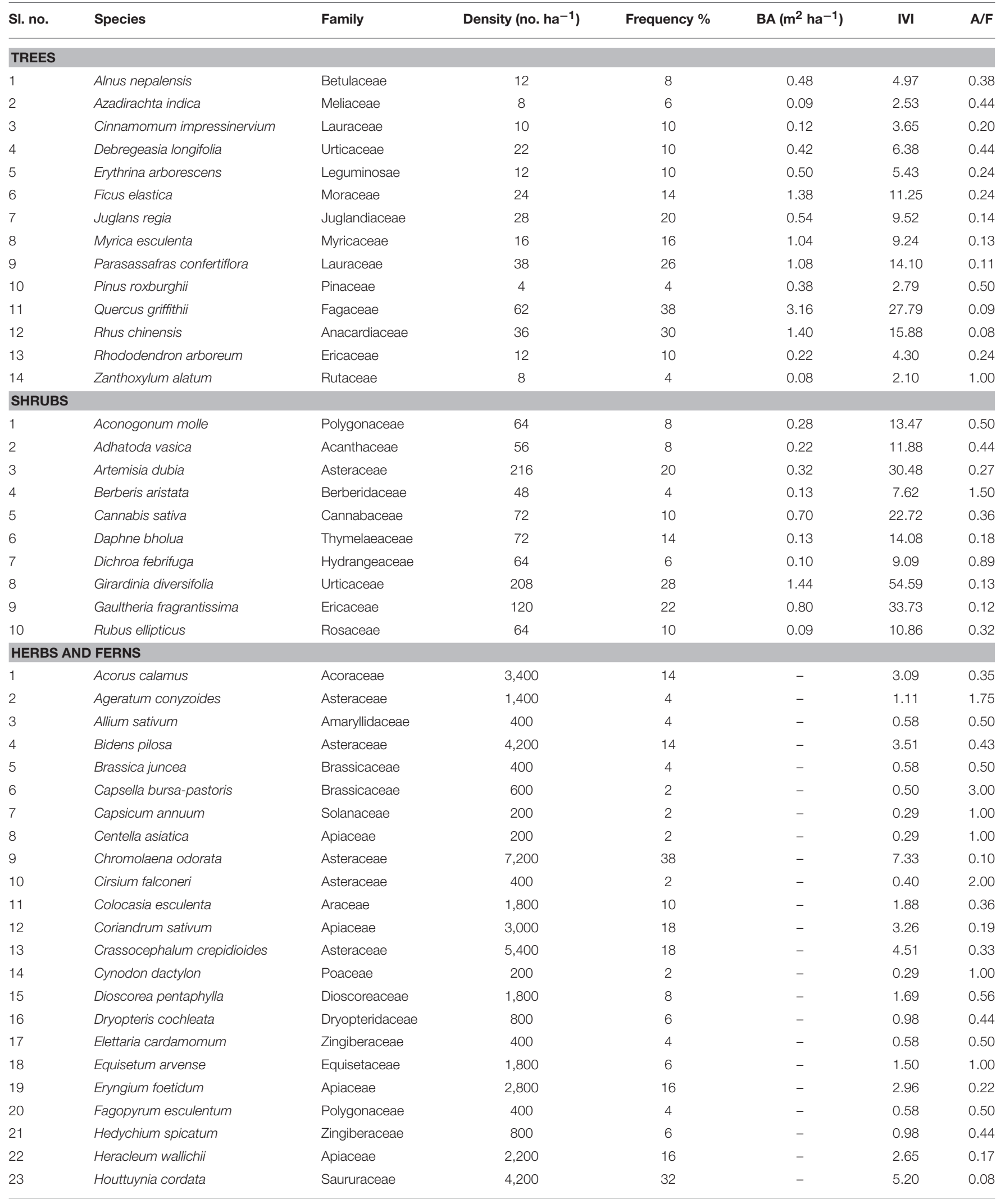


TABLE 1 | Continued

\begin{tabular}{|c|c|c|c|c|c|c|c|}
\hline SI. no. & Species & Family & Density (no. ha-1) & Frequency \% & BA $\left(m^{2} h a^{-1}\right)$ & IVI & A/F \\
\hline 24 & Lycopodium spp. & Lycopodaceae & 4,200 & 18 & - & 3.88 & 0.26 \\
\hline 25 & Nephrolepis cordifolia & Nephrolepidaceae & 3,600 & 30 & - & 4.70 & 0.08 \\
\hline 26 & Oryza sativa & Poaceae & 400 & 4 & - & 0.58 & 0.50 \\
\hline 27 & Paris polyphylla & Melanthiaceae & 6,800 & 56 & - & 8.81 & 0.04 \\
\hline 28 & Physalis divaricata & Solanaceae & 3,200 & 18 & - & 3.36 & 0.20 \\
\hline 29 & Plantago depressa & Plantaginaceae & 200 & 2 & - & 0.29 & 1.00 \\
\hline 30 & Raphanus sativus & Brassicaceae & 400 & 4 & - & 0.58 & 0.50 \\
\hline 31 & Rumex nepalensis & Polygonaceae & 4,600 & 16 & - & 3.90 & 0.36 \\
\hline 32 & Solanum nigrum & Solanaceae & 2,600 & 14 & - & 2.67 & 0.27 \\
\hline 33 & Swertia chirata & Gentianaceae & 13,400 & 56 & - & 12.25 & 0.09 \\
\hline 34 & Taraxacum officinale & Asteraceae & 200 & 2 & - & 0.29 & 1.00 \\
\hline 35 & Tupistra nutans & Asparagaceae & 2,400 & 12 & - & 2.38 & 0.33 \\
\hline 36 & Urtica dioica & Urticaceae & 3,800 & 16 & - & 3.48 & 0.30 \\
\hline 37 & Xanthium strumarium & Asteraceae & 3,400 & 26 & - & 4.22 & 0.10 \\
\hline 38 & Zingiber officinale & Zingiberaceae & 200 & 2 & - & 0.29 & 1.00 \\
\hline \multicolumn{8}{|c|}{ CLIMBERS } \\
\hline 1 & Crawfurdia speciosa & Gentianaceae & 10 & 4 & - & 4.99 & 1.25 \\
\hline 2 & Dendrobium crumenatum & Orchidaceae & 22 & 14 & - & 13.53 & 0.22 \\
\hline 3 & Drynaria propinqua & Polypodiaceae & 18 & 2 & - & 6.43 & 9.00 \\
\hline 4 & Holboellia latifolia & Berberidaceae & 22 & 16 & - & 14.51 & 0.17 \\
\hline 5 & Pisum sativum & Leguminosae & 6.0 & 4.0 & - & 3.78 & 0.75 \\
\hline 6 & Rubia cordifolia & Rubiaceae & 50 & 34 & - & 31.82 & 0.09 \\
\hline 7 & Viscum nepalense & Santalaceae & 26 & 18 & - & 16.70 & 0.16 \\
\hline
\end{tabular}

$B A$, Basal area $\left(\mathrm{GBH}^{2} / 4 \pi\right)$; IVI, Important Value Index; $\mathrm{A} / \mathrm{F}$, Abundance-to-frequency ratio. GBH of trees and shrubs were measured at $1.37 \mathrm{~m}$ and $2 \mathrm{~cm}$ above the ground, respectively.

TABLE 2 | Diversity attributes of trees, shrubs, herbs, and ferns and climbers in the broad-leaf coniferous forests of Tshothang Chiwog, Bhutan.

\begin{tabular}{|c|c|c|c|c|c|c|c|c|}
\hline Life form & No. of species ha ${ }^{-1}$ & Number of individuals $\mathrm{ha}^{-1}$ & Basal area $\left(\mathrm{m}^{2} \mathrm{ha}^{-1}\right)$ & IVI & D & $\mathbf{H}^{\prime}$ & Hmax & $\mathbf{E}$ \\
\hline Trees & 38 & 784 & 24.86 & 300 & 0.95 & 4.86 & 5.08 & 0.95 \\
\hline Shrubs & 19 & 1448 & 5.38 & 300 & 0.92 & 3.97 & 4.11 & 0.96 \\
\hline Herbs/ferns & 85 & 191600 & - & 200 & 0.97 & 5.82 & 6.19 & 0.94 \\
\hline Climbers & 15 & 330 & - & 200 & 0.92 & 3.69 & 3.87 & 0.95 \\
\hline
\end{tabular}

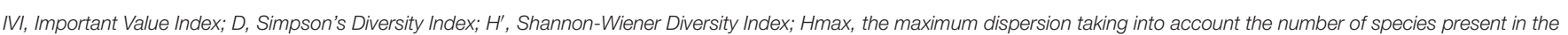
plot (Hmax $=3.3219 \log _{10} S$, where $S$ is the total number of species), E, Equitability (Where $E=H^{\prime} / H$ max).

\section{Vegetation Structure of Trees and Shrubs}

Girth frequency distribution showed a characteristic inverse J-shaped distribution pattern implying a negative exponential relationship between density and size classes, implying adequate regeneration potential for the woody flora (Figure 2). The GBH class of 15 to $29 \mathrm{~cm}$ had the highest number of individuals for tree species. Q. griffithii, B. grossa, L. elegans, walnut (Juglans regia) and prickly ash (Zanthoxylum bungeanum) were the predominant species in this size class (data not presented). The GBH distribution pattern of shrubs also showed an inverse Jshaped pattern, except for the GBH class 0 to $5 \mathrm{~cm}$, which was truncated (Figure 3), implying poor regeneration status of the smallest size class, which is a matter of concern.

\section{Ethnobotanical and Socioeconomic Aspects}

The ethnobotanical study documented 55 MPs representing 37 families, which included 27 herbaceous plants, 15 trees, eight shrubs and five climbers (Table 3). The most species-rich families were: Asteraceae (five spp.), Lauraceae and Polygonaceae (three spp. each). The data presented in Table 3 also indicate that MPs are important in the local health care delivery system. As much as $67.5 \%$ of respondents reportedly used MPs to cure various ailments like cold, cough, headache, body pain, wounds, blood pressure, etc. (data not presented). The farmers in the focus group have indicated as their opinions that $S$. chirata, A. dubia, C. odorata, and V. nepalense are the commonly used MPs for treating diseases like headache, cough and cold, body pain, and stomach ache. At the national scale, some of these plants are also used for drug discovery, which is known to cure a wide array of diseases. Local people deemed MPs complementary to western medicine.

Medicinal plants also have cultural significance. In fact, the traditional belief systems of the local people (e.g., giving protection from evil spirits) are intricately inter-woven with MP usage in this locality. Species like tree rhododendron 


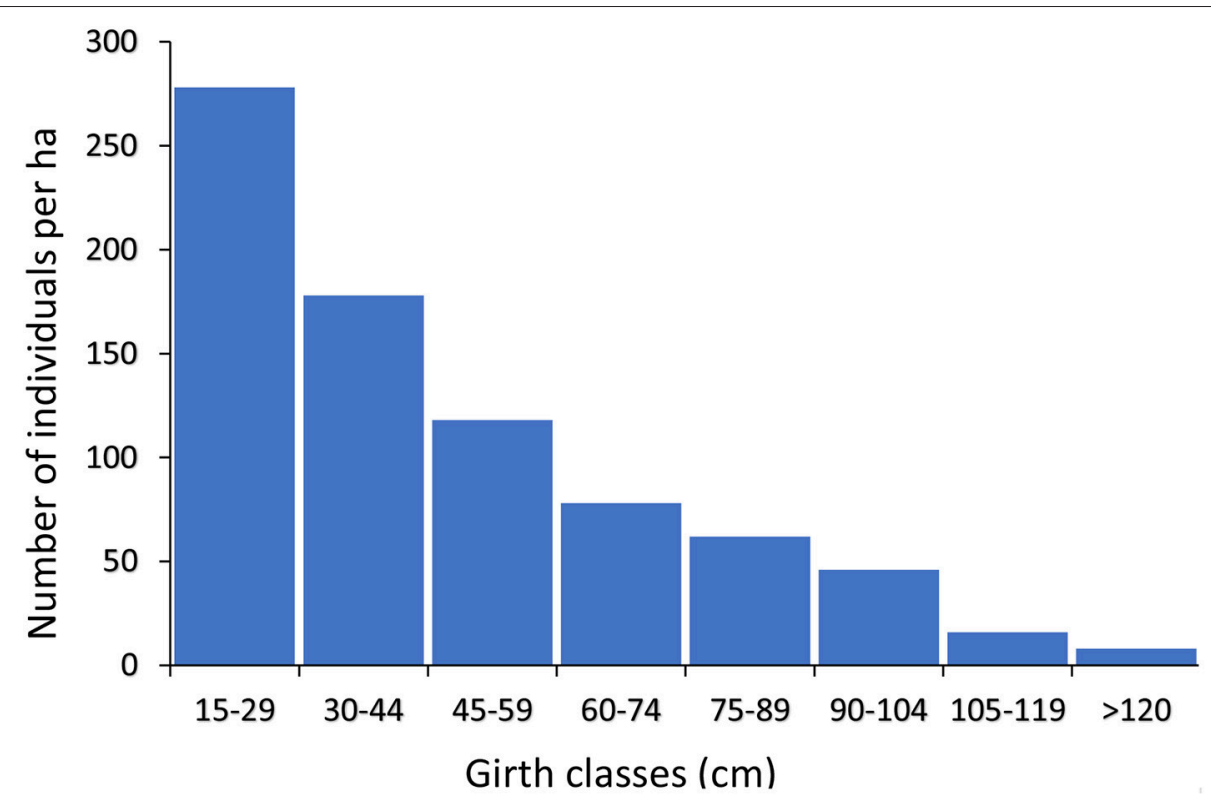

FIGURE 2 | Girth frequency distribution of trees ( $\geq 15 \mathrm{~cm}$ girth at breast height) in the broad-leaf mixed coniferous forest of Tshothang Chiwog, Bhutan.

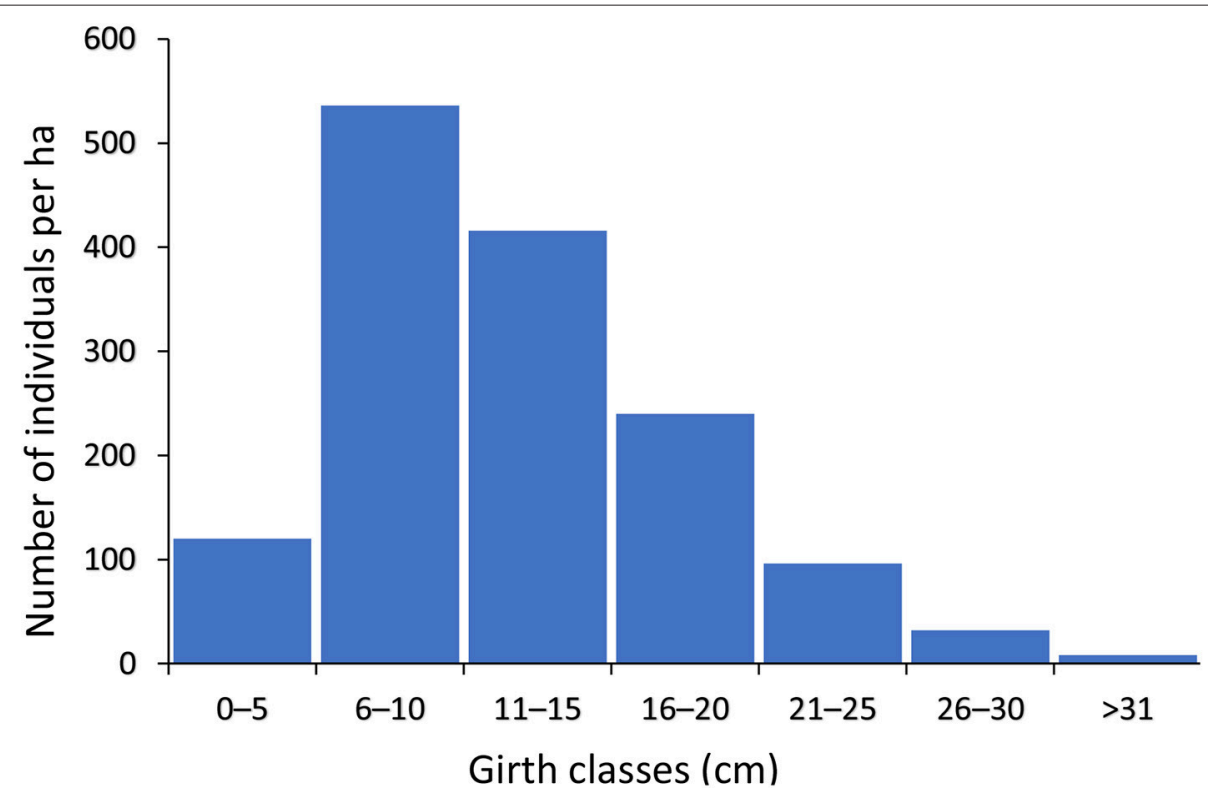

FIGURE 3 | Girth frequency distribution of shrubs (low woody perennials generally $<5 \mathrm{~m}$ height) measured at $2 \mathrm{~cm}$ above ground in the broad-leaf mixed coniferous forest of Tshothang Chiwog, Bhutan.

(Rhododendron arboretum), oriental thuja (Thuja orientalis), Japanese cedar (Cryptomeria japonica), and A. dubia are used for making smoke (Saang) every morning and evening to ward off evil spirits. Consistent with the tenets of Mahayana sect of Buddhism, it is believed that smoke drives away evils and devils, and serves as a remedy for quenching thirst and hunger of evils and devils. Furthermore, several species of Cupressus spp. and Juniperus spp. are traditionally used for making the mainline or life tree (Sog-shing) in prayer wheels, stupa (Choertens) and statues. Circumambulating and rotating prayer wheels and stupa may accumulate good fortune, purify one's soul, make them healthier and enable them to live longer.

A total of 40 farmers were randomly interviewed (75\% male and $25 \%$ female) to assess the socioeconomic status of MP collectors in Tshothang Chiwog. The average age of the respondents fell in the range of 23 to 78 years with a mean of 
TABLE 3 | List of medicinal plant species in the broad-leaf mixed coniferous forests of Tshothang Chiwog, Lauri Gewog, Bhutan, and the ethnobotanical knowledge associated with them elucidated from the survey.

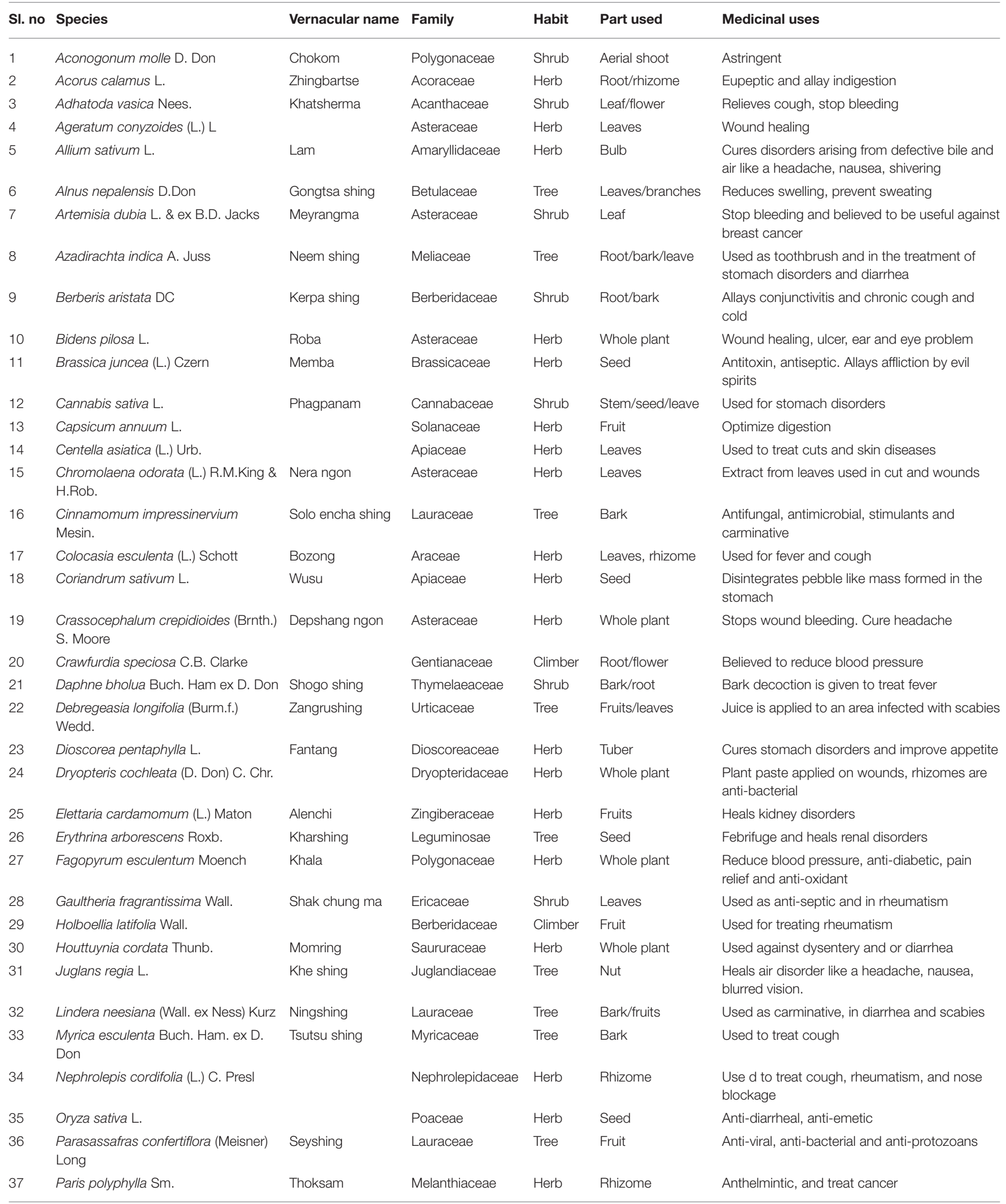


TABLE 3 | Continued

\begin{tabular}{|c|c|c|c|c|c|c|}
\hline SI. no & Species & Vernacular name & Family & Habit & Part used & Medicinal uses \\
\hline 38 & Pinus roxburghii Sarg. & Lentshong shing & Pinaceae & Tree & Resin/leaves & Resins are anti-septic, anti-uretic and vermifuge \\
\hline 39 & Pisum sativa L. & & Leguminosae & Climber & Seed & $\begin{array}{l}\text { Cures disorders like a headache, blurred vision } \\
\text { and nausea. }\end{array}$ \\
\hline 40 & Platago depressa Willd. & & Plantaginaceae & Herb & Whole plant & Used for treating diarrhea \\
\hline 41 & Prunus persica (L.) Batsch & & Rosaceae & Tree & Nut & Hydragogue \\
\hline 42 & $\begin{array}{l}\text { Quercus griffithii Hoof.K. \& Thomson } \\
\text { ex Miquel }\end{array}$ & Bainang shing & Fagaceae & Tree & Nut & Anti-diarrheal \\
\hline 43 & Raphanus sativus L. & & Brassicaceae & Herb & Root & Allays asthma and cure lung infection \\
\hline 44 & Rhododendron arboreum Sm. & Sangshing & Ericaceae & Tree & Flower/leaves & Treats dysentery, diarrhea and headache \\
\hline 45 & Rhus chinensis Miller & Roptang shing & Anacardiaceae & Tree & Fruit & Purgative, emetic and appetizer. \\
\hline 46 & Rubia cordifolia L. & Laniru & Rubiaceae & Climber & Stem & $\begin{array}{l}\text { Hematinic and heals blood disorders. Allays } \\
\text { fever }\end{array}$ \\
\hline 47 & Rubus ellipticus Sm. & & Rosaceae & Shrub & Bark & Heals common cold \\
\hline 48 & Rumex nepalensis Spreng & Bamlakpa & Polygonaceae & Herb & Root & Used against hair loss \\
\hline 49 & Solanum nigrum L. & & Solanaceae & Herb & Fruit/root & $\begin{array}{l}\text { Used to control vomiting, diarrhea, reduce mild } \\
\text { abdominal pain }\end{array}$ \\
\hline 50 & Swertia chirata (Roxb.) Karsten & Khalu & Gentianaceae & Herb & Whole plant & Cures headache, fever, cold and cough \\
\hline 51 & Tupistra nutans Wall. ex Lindl & & Asparagaceae & Herb & Flower & Used as appetizer \\
\hline 52 & Urtica dioica L. & Jazzu & Urticaceae & Herb & Root/whole plant & Paste is applied on minute fracture \\
\hline 53 & Viscum nepalense Spreng & Neyshing jorma & Santalaceae & Climber & Whole plant & Vasodilation, sedative, diuretic, and anti-cancer \\
\hline 54 & Zanthoxylum alatum Roxb. & & Rutaceae & Tree & Fruits & $\begin{array}{l}\text { Blood vessel dilator, allay itching caused by } \\
\text { dermatological diseases }\end{array}$ \\
\hline 55 & Zingiber officinale Roscoe & & Zingiberaceae & Herb & Rhizome & Anti-microbial and appetizer \\
\hline
\end{tabular}

46.2 years. Only five of the total 40 respondents had completed primary education and the remaining 35 did not attend school. Average size of the household was four. In the opinion of the respondents, MP collection is an important income generating activity for the local community. Accordingly, farmers were actively engaged in collecting and selling MPs. Thirty one of our 40 respondents $(77.5 \%)$ collected MPs. The most important commercial MPs were: S. chirata, P. polyphylla, R. cordifolia, and $V$. nepalense. MPs were predominantly collected during the winter season (December to February), either by father $(38 \%)$, mother $(5 \%)$, children $(27 \%)$ or both father and children (8\%). Farmers also sold the MPs either in the local markets of Woongthi and Jomotshangkha, or to the traders from the Indian State of Arunachal Pradesh. P. polyphylla and S. chirata were the chief MP resources sold to the MP traders of Arunachal Pradesh, which enable the collectors to fetch premium prices. The annual income of such farmers apparently ranged from 30 to 330 USD, and the higher returns improved their socioeconomic status, especially during the last couple of years.

\section{DISCUSSION}

\section{Floristic Attributes}

Tshothang Chiwog is characterized by high floristic richness and diversity and abundant MP wealth (Appendix 1 in Supplementary Material; Tables 1-2). In general, the Himalayan forests are characterized by high species richness, diversity and play a significant role in providing many ecosystems services (Chettri et al., 2010). However, anthropogenic factors including climate change are affecting the structure and composition of these forest types and their capacity to provide ecosystem services, including the ability of these forests to provide MPs to meet the society's requirement (Hamilton and Radford, 2007; ICIMOD, 2009). The anthropogenic impacts on the structure and composition of forests are variable from locality to locality, depending on the magnitude of these disturbances. Although some studies have addressed this concern in the north-western Himalayan context (Pant and Samant, 2012; Hanief et al., 2016), such studies have been rarely undertaken in Bhutan (Wangchuk et al., 2016).

The total number of tree and shrub species (woody species richness) presently reported from the broad-leaf mixed coniferous forest of Tshothang Chiwog, Bhutan (Appendix 1 in Supplementary Material; Table 2) can be compared to that of Dochula Pass, Bhutan (123 species ha ${ }^{-1}$; Wangda and Ohsawa, 2006) and Yakpagang Community Forest in Mongar, Bhutan (150 species ha ${ }^{-1}$; Buffum et al., 2008). Although 69 MP species occurred at the site (Table 1), only five MPs were commercially exploited (author's observations). The top most species in this respect were: $S$. chirata, P. polyphylla, R. cordifolia, $P$. confertiflora, and $V$. nepalense. The total number of MPs in the present study was greater than that of what Namsa et al. (2011) reported for Sikkim (50 plants species belonging to 29 families used for treating 22 human and four veterinary ailments) and lower than that of what Wangchuk et al. (2011) earlier reported for Bhutan (113 lower elevation medicinal plants). Species composition is often determined and regulated by an array of ecological, environmental, edaphic and anthropogenic factors 
(Muraleedharan et al., 2005). The occurrence of a large number of plant species in the study area is presumably because of the prevalence of many micro-habitats in the mountainous terrain. The density of trees and shrubs reported from the study site is similar to that of the broad-leaf forests of Dagana Dzongkhag, Bhutan (662 individuals $\mathrm{ha}^{-1}$; Tenzin and Hasenauer, 2016) and the stand basal area similar to that of the logged over plots of Chimithanka within Gidakom Forest Management Unit, Bhutan (29.77 $\mathrm{m}^{2} \mathrm{ha}^{-1}$; Covey et al., 2015). The stand basal area, however, was less than that of a humid mixed conifer forest at Dochula Ridge Top, Bhutan $\left(66.4 \mathrm{~m}^{2} \mathrm{ha}^{-1}\right.$; Wangda and Ohsawa, 2006).

The plant distribution pattern in the study location ranged from random to contagious (highly aggregated distribution). According to Odum (1971), contagious distribution is the commonest, random distribution is found only in a uniform environment, and regular distribution occurs when severe competition occurs between individuals. Hanief et al. (2016) reported similar observations (A/F: 0.01 to 0.08 ) from the Darhal watershed in Jammu and Kashmir Himalayas, India.

Species diversity contributes to ecosystem richness (Muraleedharan et al., 2005). Herbaceous flora exhibited the highest diversity and species richness followed by trees, shrubs, and climbers, as expected. The Simpson and ShannonWeiner diversity index ranged from 0.92 to 0.97 and 3.69 to 5.82, respectively (Table 2 ). High diversity in the study site can be explained by the low to moderate levels of disturbances occurring at the site such as MP collection, grazing etc. This is perhaps consistent with the "intermediate disturbances" hypothesis of Connell (1978), according to which stress limits species at the lower end of the disturbance gradient, whereas increased competition is the limiting factor at the upper end of the gradient. Tenzin and Hasenauer (2016), reported similar diversity $\left(D=0.88\right.$ and $\left.H^{\prime}=3.39\right)$ for the broad-leaf forests of Dagana, Bhutan. Overall, the floristic composition, diversity, and vegetation structure are comparable to other studies within Bhutan and the north-western Himalayan region (Buffum et al., 2008; Wangchuk, 2013; Wangchuk and Gurung, 2016).

The poor regeneration status of shrub species in the lower size classes (Figure 3) is presumably because of occurrence of constraints like ground fire, browsing, and livestock grazing, which affects the shrubs more than the trees. According to Narayanan and Swarupanandan (1996), fire kills the young seedlings and encourages the invasion of seedlings and saplings. It also causes damages and loss of species richness and diversity (Buffum et al., 2008; Wangchuk, 2013; Wangchuk and Gurung, 2016). Cattle and yaks are major sources of grazing pressure in the study area (author's observations). It was also reported that farmers collect shrubs like Sikkim knotweed (Aconogonum molle) and A. dubia for fodder and green manure purposes.

\section{Ethnobotanical and Socioeconomic Aspects}

An array of MP resources are utilized in the study locality and adjoining areas of Bhutan for curing various ailments and the indigenous knowledge system appears to be profound in this respect (55 species; Table 3). The number of MP species presently reported, however, was marginally lower than that from the results of the vegetation study (69 species; Table 1). Such differences are plausible in view of the differences in experience and knowledge of the respondents and the investigators. The concordance between ethnobotanic and vegetation studies for the most species-rich families was also less evident. For example, Asteraceae, Lauraceae, and Polygonaceae formed the dominant plant families (with more than three plants per family) according the ethnobotanical survey (Table 3), while the speciesrich families of medicinal plants according to the vegetation analysis were: Asteraceae, Polygonaceae, Apiaceae, Brassicaceae, Zingiberaceae, and Urticaceae (Table 1).

Apart from the medicinal uses, MPs are also used in drug discovery in the indigenous Bhutanese medical systems. Indeed, there are two indigenous medical systems prevailing in the country. These are: (i) the formalized traditional medicine system- gSo-ba rig-pa (pronounced as So-wa Rig-pa) and (ii) the traditional local healing practices or folk medicine (Nangpai mempa). gSo-ba rig-pa is a codified medical system in the country, which is estimated to use over 200 species of MPs, 35 different types of animal parts and 18 different types of minerals to produce 103 types of drugs (Jamphel, 2011; Choden and Dorji, 2014). The traditional healing practices, however, are transmitted through oral traditions from either father to son or from elderly to young and lacks proper documentation; but uses a wide spectrum of MPs. Regarding the choice of MPs in the indigenous medical systems, factors such as ease of collection, accessibility, and affordability appear to be major determinants (Pannozzo et al., 2012). Results of our ethnobotanical study (e.g., medicinal and other uses of plant resources: Table 3) are comparable to what Namsa et al. (2011) documented previously for the Monpa tribe of Kalaktang, Arunachal Pradesh, India, and Prakash (2011) for the tribals of Uttar Pradesh in India, implying strong similarities in the usage of MP resources by the tribal communities of the Eastern Himalayan belt. Apart from this, MPs in Bhutan have been a cardinal source of food and food supplements, socioeconomic and religious uses too (Wangchuk et al., 2008; Wangchuk and Olsen, 2011).

Traditionally, the economic well-being and social status of the rural community of Lauri Gewog is dependent on MP collection (Pannozzo et al., 2012). Accordingly, farmers were actively engaged in collecting and selling MPs. However, the way in which local people collect MPs are dependent on the commercial value it fetches in the market. Although 55 MPs were documented through participatory discussion (Table 3), only five species are commercially exploited. These are: S. chirata, P. polyphylla, $R$. cordifolia, V. nepalense, and $P$. confertiflora. The annual income of farmers from MP collection ranged from USD 30 to 330. Wangchuk and Gurung (2016) reported that farmers of Lingzhi and Langthel of western and central Bhutan had also improved their socioeconomic status by the collection of MPs. Studies in Nepal (Ghimire, 2008), and South India (Muraleedharan et al., 2005) also reported similar trends.

The respondents also opined that MP resources in the Chiwog have been diminishing over the years. According to some estimates, in the year 2000, farmers collected as much as 20 
tonnes of MPs, chiefly S. chirata. However, it dropped to less than five tonnes by 2006 (Pannozzo et al., 2012), presumably because of the reduced availability in the wild. The situation has further deteriorated now. S. chirata, I. griffithii, Indian bay leaf (Cinnamomum impressinervium), and P. polyphylla are apparently threatened in this locality, as informed by the respondents. Most farmers ( $45 \%$ respondents), cited the ban on shifting cultivation, illegal poaching, encroachment by others (highlanders), forest fires and grazing as probable reasons for the declining MP wealth. More importantly, it could be due to overharvesting and unsustainable extraction. Although the declining resources warrant domestication of the prominent MPs, none of the respondents except one had successfully cultivated MPs, particularly S. chirata.

Most notably, the way in which local people collect MPs are dependent on their usages and the commercial value it fetches in the market. Farmers highlighted the challenges of lack of farm roads for carrying the produce to the markets and the distance to market as hindrances in getting reasonable returns. Similar difficulties and challenges were reported by Pannozzo et al. (2012) for marketing MPs in another location of Lauri Gewog. Poor accessibility to markets especially for Tamang in Sandhu Marunche and Kanche CF User Groups in Lamjung district of Nepal also resulted in greater dependence on intermediaries and lower sale prices for the MP resources (Gaire, 2005).

The method of MP extraction also has changed over a period of time. Traditionally, farmers of Tshothang Chiwog selectively collected tubers, fruits, or climbers using simple tools such as hoe and knife/sickle. Xhosa and Sotho people of South Africa, also used similar tools to collect MPs (Liu et al., 2007). And the traditional method of extraction is often regarded as eco-friendly. However, contradictory practices were observed in the study area. For example, whole trees were cut down to collect fruits of $P$. confertiflora and $V$. nepalense, primarily to avoid the effort of climbing (author's observation). Similarly, the bark was destructively removed from Cinamomum impressinervium. Rhizomes of $P$. polyphylla also were dug out extensively. These practices would eventually deplete the MP resources of Tshothang Chiwog. Other workers also reported that MPs in some localities of Bhutan have been shrinking over the years (e.g., Wangchuk and Tobgay, 2015). Rai et al. (2000) and Muraleedharan et al. (2005) also reported that overexploitation is a principal reason for the shrinking non-wood forest product resources in Sikkim Himalayas and Western Ghats of India, respectively.

Furthermore, there are no management plans, rules, and regulations for extraction, storage, and utilization of MPs in the Chiwog. The only rule available (formulated within the villages) and that is orally transmitted among the villagers is with respect to the time of collection (when and for how long to collect MPs) and the number of collectors (viz. how many people from each household are allowed to collect MPs). The respondents were also not aware of any collection guidelines for MPs. Interestingly, all respondents (100\%) favored the formulation of management rules, strategies, and plans for MP extraction, implying that the farmers are well aware of negative anthropogenic impacts on MPs, although their practices do not corroborate with that line of thinking. The solution to vexed problems such as over-exploitation of MP resources in Bhutan and associated threats to local and regional biodiversity, may lie in carrying out advocacy and awareness programmes, formulating stringent policies for better MP resource management and domestication of the more valuable MPs (e.g., S. chirata and P. polyphylla).

\section{CONCLUSIONS}

Results of the present study underscore the fact that Tshothang Chiwog harbors a considerable number of plant species, which are of ethnobotanical and cultural significance. Broad-leaf mixed coniferous forest, which is the predominant forest type of this locality, is endowed with high diversity, species richness, and adequate regeneration potential of the woody flora. Results of the socio-economic survey indicated that medicinal plant collection, in general, have improved the socioeconomic status and livelihood security of the local inhabitants. However, the Chiwog lacks proper guidelines and regulations for MP collection, because of which the farmers often resort to overextraction, threatening the sustainability of the MP resources. Hence, it is vital to implement rigorous plans and policies for the management and surveillance of MP resources in this and other localities of Bhutan. Yet another strategy to augment MP resources is to domesticate the prominent species such as $S$. chirata and $P$. polyphylla. However, no serious attempts have been made in this direction till now at the study location or elsewhere in the country. Although our data pertain to one location in south-east Bhutan, the results may have wider applicability over other locations with similar edaphic characteristics, climatic regimes and floristic spectrum.

\section{AUTHOR CONTRIBUTIONS}

NJ and BK: conceived the study; NJ with the help of the field survey teams conducted the survey; NJ and BK: analyzed the data and prepared the manuscript; BK: revised the manuscript.

\section{FUNDING}

Financial support in the form of a fellowship was provided to the senior author by Nalanda University for undergoing Master's program.

\section{ACKNOWLEDGMENTS}

This work forms a part of the MSc dissertation project of the first author, who acknowledges the financial support provided by Nalanda University for undergoing the Master's program. The authors thank the members of field survey teams and the respondents of the socioeconomic survey for their help. Mr. Salai K. Chha Nge assisted in the preparation of the GIS map of Tashothang Chiwog.

\section{SUPPLEMENTARY MATERIAL}

The Supplementary Material for this article can be found online at: https://www.frontiersin.org/articles/10.3389/fenvs. 2017.00096/full\#supplementary-material 


\section{REFERENCES}

Buffum, B., Gratzer, G., and Tenzin, Y. (2008). Forest grazing and natural regeneration in a late successional broadleaved Community Forest in Bhutan. Mt. Res. Dev. 29, 30-35. doi: 10.1659/mrd.991

Chettri, N., Sharma, E., Shakya, B., Thapa, R., Bajracharya, B., Uddin, K., et al. (2010). Biodiversity in the Eastern Himalayas: Status, Trends and Vulnerability to Climate Change. Climate Change Impact and Vulnerability in the Eastern Himalayas- Technical Report 2. ICIMOD, 1-24.

Choden, D., and Dorji, P. (2014). Shortage of medicines in the traditional medicine units: a case study. Menjong Sorig J. 6, 24-30.

Connell, J. H. (1978). Diversity in tropical rain forests and coral reefs. Science 199, 1302-1310. doi: 10.1126/science.199.4335.1302

Covey, K., Carroll, C. J. W., Dugid, M. C., Dorji, K., Dorji, T., Tashi, S., et al. (2015). Developmental dynamics following selective logging of an evergreen oak forest in the Eastern Himalaya, Bhutan: structure, composition, and spatial pattern. For. Ecol. Manag. 336, 163-173. doi: 10.1016/j.foreco.2014.10.006

Curtis, J. T., and McIntosh, R. P. (1950). The interrelations of certain analytic and synthetic phytosociological characters. Ecology 31, 434-455. doi: $10.2307 / 1931497$

Daniels, R. J. R., Gadgil, M., and Joshi, N. V. (1995). Impacts of human extraction in tropical forests in the Western Ghats in Uttara Kannada, South India. J. Appl. Ecol. 32, 866-874. doi: 10.2307/2404826

FAO (1996). Non-wood Forest Products of Bhutan. The Food and Agriculture Organization of the United Nations Bangkok.

FAO-UNESCO (1977). FAO-UNESCO Soil Map of the World 1: 5000000 Volume VII South Asia. UNESCO Paris, 117.

Gaire, D. (2005). An Assessment of Non-timber Forest Products Marketing in Community Forests: A Case Study from Lamjung District. Project Paper. Tribhuvan University, Institute of Forestry, Pokhara, 53.

Ghimire, S. K. (2008). "Medicinal plants in the Nepal Himalaya: Current issues, sustainable harvesting, knowledge gaps, and research priorities," in Medicinal Plants in Nepal: An Anthology of Contemporary Research, eds O. S. Jha, S.B. Karmacharya, M. K. Chettri, C. B. Thapa, and B. B. Shrestha (Kathmandu: Ecological Society), 25-42.

Govil, K. (1999). FRA 2000 Forest Resources of Bhutan, Country Report. Forestry Department, Food and Agriculture Organization of the United Nations. Forest Resources Assessment Programme, Working Paper, Rome, 14, 1-50.

Grierson, A. J. C., and Long, D. G. (1991). Flora of Bhutan: Including a Record of Plants from Sikkim, Vol. 1, Part 1. Edinburgh: Royal Botanic Garden.

Hamilton, A. C., and Radford, E. A. (2007). Identification and Conservation of Important Plant Areas for Medicinal Plants in Himalaya. Plantlife International (Salisbury, UK) and Ethnobotanical Society of Nepal, Kathmandu, 1-42.

Hanief, A., Bidalia, A., Meena, A., and Rao, K. S. (2016). Natural regeneration dynamics of dominant tree species along an altitudinal gradient in three different forest covers of Darhal watershed in north-western Himalaya (Kashmir), India. Trop. Plant Res. 3, 253-262.

International Centre for Integrated Mountain Development (ICIMOD) (2009). Proceedings of the International Mountain Biodiversity Conference- Biodiversity Conservation and Management for Enhanced Ecosystem Services: Responding to the Challenges of Global Change, ed E. Sharma (Kathmandu: ICIMOD), 1-3.

Jamphel, K. (2011). Report on survey of low altitude medicinal plants of Phankhar, Goshing and Ngangla Gewogs under Panbang Drungkhag. Menjong Sorig J. 4, 23-38.

Kala, C. P. (2005). Indigenous uses, population density, and conservation of threatened medicinal plants in protected areas of the Indian Himalayas. Cons. Biol. 19, 368-378. doi: 10.1111/j.1523-1739.2005.00602.x

Liu, F., Vind, J., Promchote, P., and Ly, P. (2007). Medicinal Plants, Its Condition and Socio-Economic Impacts - A Case Study in Makomereng and Pepela, South Africa. Interdisciplinary Land Use and Natural Resource Management, 102.

Muraleedharan, P. K., Sasidharan, N., Kumar, B. M., Sreenivasan, M. A., and Seethalakshmi, K. K. (2005). Non-timber forest products in the Western Ghats of India: Floristic attributes, extraction, and regeneration. J. Trop. For. Sci. 17, 243-257.

Murali, K. S., Uma, S., Uma, S. R., Ganeshaiah, K. N., and Bawa, K. S. (1996). Extraction of non-timber forest products of Biligiri Rangan Hills, India. 2 Impacts of NTFP extraction on regeneration, population structure and species composition. Econ. Bot. 50, 252-269. doi: 10.1007/BF02907329
Namsa, N. D., Mandal, M., Tangjang, S., and Mandal, S. C. (2011). Ethnobotany of the Monpa ethnic group at Arunachal Pradesh, India. J. Ethnobiol. Ethnomed. 7:31. doi: 10.1186/1746-4269-7-31

Narayanan, I. V., and Swarupanandan, K. (1996). Regeneration dynamics and sylvigemnesis in the moist deciduous forests of southwest India. New For. 11, 185-205.

National Environment Commission (NEC) (2016). Bhutan State of the Environment Report 2016. National Environment Commission, Royal Government of Bhutan, Thimphu, 124.

Nepstad, D. C., Brown, I. F., Luz, L., Alechandre, A., and Viana, V. (1992). "Biotic impoverishment of Amazonian forests by rubber tappers, loggers, and cattle ranchers," in Non-timber Forest Products from Tropical Forests: Evaluation of a Conservation and Development Strategy, Vol. 9, Advances in Economic Botany, eds D. C. Nepstad and S. Schwartzman (Brony, NY: The New York Botanical Garden), 1-14.

Ngawang, R. (1996). "Medicinal Plants," in Non-wood forest products of Bhutan (Bangkok: The Food and Agriculture Organization of the United Nations), $21-41$.

Odum, E. P. (1971). Fundamentals of Ecology. Philadelphia, PA: W. B. Saunders.

Pannozzo, L., Hayward, K., Om, T., Raftis, L., Morales, K., Colman, D., et al. (2012). Profile of Samdrup Jongkhar. Funded by International Development Research Centre, Canada-The Samdrup Jongkhar Initiative, GPI Atlantic, Canada. Available online at http:/gpiatlantic.org/bhutan/docs/ samdrup-jongkhar-profile-aug2.pdf (Accessed September 25, 2017).

Pant, S., and Samant, S. S. (2012). Diversity and regeneration status of tree species in Khokhan Wildlife Sanctuary, north-western Himalaya. Trop. Ecol. 53, 317-331.

Paul, A., Gajurel, P. R., and Das, A. K. (2015). Threats and conservation of Paris polyphylla an endangered, highly exploited medicinal plant in the Indian Himalayan region. Biodiveritas 16, 295-302. doi: 10.13057/biodiv/d1 60226

Prakash, A. (2011). "Uses of some threatened and potential ethnomedicinal plants among the tribal of Uttar Pradesh and Uttarakhand in India," in National Conference on Forest Biodiversity: Earth's Living Treasure (Lucknow), 93-99.

Rai, L. K., Prasad, P., and Sharma, E. (2000). Conservation threats to important medicinal plants of the Sikkim Himalaya. Biol. Cons. 93, 27-33. doi: 10.1016/S0006-3207(99)00116-0

Robbins, C. S. (2000). Comparative analysis of management regimes and medicinal plant trade monitoring mechanism for American Ginseng and Goldenseal. Cons. Biol. 14, 1422-1434. doi: 10.1046/j.1523-1739.2000.99100.x

Roberson, E. (2008). Medicinal Plants at Risk. Tucson, AZ: Center for Biological Diversity. Available online at: www.biologicaldiversity.org (Accessed November 29, 2017).

Runk, J. V. (1998). Productivity and sustainability of a vegetable ivory palm (Phytelphasaequatoralis, Arecaceae) under three management regimes in north-western Ecuador. Econ.Bot. 52, 168-182. doi: 10.1007/BF02861205

Shankar, U., Hegde, R., and Bawa, K. S. (1998). Extraction of non-timber forest in the forests of Biligiri Rangan Hills, India. 6. Fuelwood pressure and management options. Econ. Bot. 52, 320-336. doi: 10.1007/BF02862151

Simpson, E. H. (1949). Measurement of Diversity. Nature 163:688. doi: $10.1038 / 163688 \mathrm{a} 0$

State of an Environment (2007). List of medicinal and aromatic plants grown and found in Sikkim. Sikkim.

Tenzin, J., and Hasenauer, H. (2016). Tree species composition and diversity in relation to anthropogenic disturbances in broad-leaved forests of Bhutan. Int. J. Biodivers. Sci. Ecosyst. Serv. Manag. 12, 274-290. doi: $10.1080 / 21513732.2016 .1206038$

Thinley, U. (2004). Know the Plants of Bhutan, 2nd Edn., Vol. 1. Thimphu: Ugyen Thinley.

Ticktin, T., Nantel, P., Ramirez, F., and Johns, T. (2002). Effects of variation on harvest limits for non-timber forest species in Mexico. Cons. Biol. 16, 691-705. doi: 10.1046/j.1523-1739.2002.00372.x

Tshering, D. (2006). "Foreword," in Proceeding of the National Workshop on Development of Non-Wood Forest Products in Bhutan (Forest Resources Development Division; Department of Forest, Ministry of Agriculture, Thimphu), 108.

Ugyen (2004). "Status of traditional medical system and medicinal plant diversity in Bhutan," in Biodiversity and Medicinal Plant Wealth of South Asian 
Countries, Country Report of Bangladesh, Bhutan, India, Iran, Maldives, Nepal, Pakistan and Sri Lanka, eds P. Pushpangadan, K. N. Nair, and M. R. Ahmad (Lucknow: National Botanical Research Institute), 11-25.

Wangchuk, K. (2013). Cattle Production Dynamics, Species Diversity and Relative Abundance of Understory Vegetation in the Mixed Conifer Forest of Bhutan. $\mathrm{Ph} . D$. dissertation, University of Natural Resources and Life Sciences, Vienna.

Wangchuk, P., and Samten (2009). Low Altitude Medicinal Plants of Bhutan-An Illustrated Guide for Practical Use. Thimphu: Pharmaceutical and Research Unit Institute of Traditional Medicine Services, Ministry of Health.

Wangchuk, P., Samten and Ugyen (2009). High Altitude Medicinal Plants of Bhutan: An Illustrated Guide for Practical Use, 1st Edn. Thimphu: Pharmaceutical and Research Unit, Institute of Traditional Medicine Services.

Wangchuk, P., Namgay, K., Gayleg, K., and Dorji, Y. (2016). Medicinal plants of Dagala region in Bhutan: their diversity, distribution, uses and economic potential. J. Ethnobiol. Ethnomed. 12, 1-18. doi: 10.1186/s13002-0160098-7

Wangchuk, P., and Olsen, A. (2011). Risk factors for the sustainability of Medicinal Plants in Bhutan. Asian Med. 6, 123-136. doi: 10.1163/157342110X606897

Wangchuk, P., Pyne, S. G., and Keller, P. A. (2011). Ethnobotanical authentication and identification of Khrog-sman (Lower elevation medicinal plants) of Bhutan. J. Ethnopharmacol. 134, 813-823. doi: 10.1016/j.jep.2011.01.034

Wangchuk, P., Thinley, J., and Dorji, Y. (2008). High altitude medicinal plants of Choekhor Gewog, Bumthang. Menjong Sorig J. 1, 29-33.
Wangchuk, P., and Tobgay, T. (2015). Contributions of medicinal plants to the Gross National Happiness and Biodiscovery in Bhutan. J. Ethnobot. Ethnomed. 11, 1-12. doi: 10.1186/s13002-015-0035-1

Wangchuk, P., and Gurung, D. B. (2016). Effect of different grazing regimes on the growth of Quercus semecarpifolia Sm. regeneration in western Bhutan Himalaya (Thimphu). J. Natural Res. Dev. 3, 32-38. doi: 10.17102/cnr. 2016.06

Wangda, P., and Ohsawa, M. (2006). Forest pattern analysis along the topographical and climatic gradient of the dry west and humid east slopes of Dochula, Western Bhutan. J. Renew. Nat. Res. 2, 1-17.

Yamane, T. (1967). Statistics: An Introductory Analysis, 2nd Edn. New York, NY: Harper and Row.

Conflict of Interest Statement: The authors declare that the research was conducted in the absence of any commercial or financial relationships that could be construed as a potential conflict of interest.

Copyright ( 2018 Jamba and Kumar. This is an open-access article distributed under the terms of the Creative Commons Attribution License (CC BY). The use, distribution or reproduction in other forums is permitted, provided the original author(s) or licensor are credited and that the original publication in this journal is cited, in accordance with accepted academic practice. No use, distribution or reproduction is permitted which does not comply with these terms. 